\title{
Comparing the minimum local anesthetic dose of ropivacaine in real-time ultrasound-guided spinal anesthesia and traditional landmark-guided spinal anesthesia: a randomized controlled trial of knee surgery patients
}

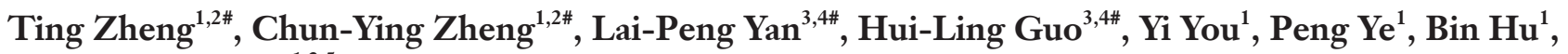 \\ Xiao-Chun Zheng ${ }^{1,2,5}$
}

${ }^{1}$ Department of Anaesthesiology, Shengli Clinical Medical College of Fujian Medical University, Fujian Provincial Hospital, Fuzhou, China; ${ }^{2}$ Department of Anaesthesiology, Fujian Provincial Hospital, Fuzhou, China; ${ }^{3}$ Department of Orthopedics, Shengli Clinical Medical College of Fujian Medical University, Fujian Provincial Hospital, Fuzhou, China; ${ }^{4}$ Department of Orthopedics, Fujian Provincial Hospital, Fuzhou, China; ${ }^{5}$ Emergency Department, Fujian Emergency Medical Center, Fujian Provincial Hospital, Fuzhou, China

Contributions: (I) Conception and design: T Zheng, CY Zheng; (II) Administrative support: XC Zheng; (III) Provision of study materials or patients: XC Zheng, T Zheng, LP Yan, HL Guo; (IV) Collection and assembly of data: Y You, P Ye; (V) Data analysis and interpretation: T Zheng, CY Zheng, B Hu; (VI) Manuscript writing: All authors; (VII) Final approval of manuscript: All authors.

\#These authors contributed equally to this work as co-first authors.

Correspondence to: Xiao-Chun Zheng. Department of Anaesthesiology, Fujian Provincial Clinical Medical College, Fujian Medical University, Fujian Provincial Emergency Centre, Fuzhou 350001, China. Email: zhengxiaochun7766@163.com.

Background: Through previous studies and clinical practice, we have found that real-time ultrasoundguided (UG) spinal anesthesia (SA) and traditional landmark-guided (LG) SA each require a different minimum local anesthetic dose (MLAD) of ropivacaine. For this study, we used Dixon's up-and-down sequential method to analyze and compare the MLAD of different ropivacaine concentrations required for the UG and LG SA methods.

Methods: A total of 120 patients undergoing knee surgery were consecutively recruited and randomly divided into four groups (30 patients per group). These groups were categorized as follows: Group I: high ropivacaine ultrasound-guided (HRUG), Group II: low ropivacaine ultrasound-guided (LRUG), Group III: high ropivacaine landmark-guided (HRLG), and Group IV: low ropivacaine landmark-guided (LRLG). SA was established by a bolus administration of up-and-down doses of $0.75 \%$ or $0.5 \%$ plain ropivacaine. Initial doses of $16,18,12$, and $14 \mathrm{mg}$ were administered to groups I-IV, and after that, increased or decreased by $1.5 \mathrm{mg}$ according to dose effectiveness. Upon identifying the intervertebral puncture level, a lumbar X-ray was performed with metal markers, and actual radiographic findings were identified and compared to the initial markings.

Results: For UG groups, the MLAD in the LRUG group was significantly higher than in the HRUG group [20.192 mg (95\% CI, 19.256-21.174) versus $17.176 \mathrm{mg}$ (95\% CI, 16.276-18.124), respectively; $\mathrm{P}<0.001]$. For LG groups, the MLAD in the LRLG group was significantly higher than in the HLRG group [14.478 mg (95\% CI, 13.364-15.500) versus $13.201 \mathrm{mg}$ (95\% CI, 11.959-14.571), respectively; $\mathrm{P}=0.047$ ]. When comparing both high ropivacaine groups (HRGs: I/III) to the low ropivacaine groups (LRGs: II/ IV), we found that both UG subgroups (I/II) had a significantly higher MLAD than LG subgroups (III/IV) $(\mathrm{P}<0.001)$. US identified L4-5 in up to $90 \%$ of cases. Comparatively, palpation was successful in only $33.3 \%$ of patients. The rates of cephalad localization by US and palpation were $6.67 \% \mathrm{vs}$. $66.67 \%$, respectively $(\mathrm{P}=0.002)$.

Conclusions: We found a higher MLAD of ropivacaine was required for UG SA at the L4-5 level due to the method providing a more accurate (less cephalad) localization than traditional LG SA.

Trial Registration: Chinese Clinical Trial Registry ChiCTR2000033158. 
Keywords: Ropivacaine; Dixon's up-and-down sequential method; minimum local anesthetic dose (MLAD); ultrasound-guided spinal anesthesia; traditional landmark-guided spinal anesthesia

Submitted Jun 23, 2021. Accepted for publication Sep 07, 2021.

doi: $10.21037 / \mathrm{atm}-21-3888$

View this article at: https://dx.doi.org/10.21037/atm-21-3888

\section{Introduction}

August Bier (1) administered the first spinal anesthesia (SA) using cocaine in 1898. Since then, traditional landmarkguided (LG) SA techniques have continued to advance for more than 130 years. At present, many studies have been conducted on the local anesthetic doses required for different surgeries when using traditional LG SA. More recently, the technique of ultrasound (US) scanning has been used to precisely locate the most suitable intervertebral space for needle entry and accurately measure the puncture depth required by assessing the anteroposterior complex. Compared with traditional LG SA, this technique greatly improves the accuracy of intervertebral space localization, reduces the number of punctures, and improves the safety and comfort of neuraxial anesthesia (2-5). The use of realtime ultrasound-guided (UG) neuraxial anesthesia was first reported in 2009 by Karmakar et al. (6) Since then, many successful reports have addressed how real-time UG SA can improve the needle entry point pathway $(7,8)$, help assess the feasibility of the method in patients with predicted difficulty during spinal puncture $(9,10)$, and assist in the needle tracking system (11). However, few studies have investigated the anesthetic dosages related to neuraxial anesthesia under real-time UG.

Ropivacaine is a long-acting pure $\mathrm{S}(-)$-isomer amide local anesthetic with low toxicity to the central nervous and cardiovascular systems. It can produce the phenomenon of sensory-motor dissociation (12) and is widely used in clinical anesthesia and postoperative analgesia. Numerous dose-related studies of ropivacaine have shown that the minimum local anesthetic dose (MLAD) of ropivacaine mostly ranges from $7.6-12.8 \mathrm{mg}$ when traditional LG SA is used in lower extremity surgery (13-16). These studies include Sell et al. (13), who determined that the median effective dose $\left(\mathrm{ED}_{50}\right)$ of ropivacaine used in hip surgery was $12.8 \mathrm{mg}$. Another study by Lee et al. $(14,15)$ showed that the $\mathrm{ED}_{50}$ of ropivacaine for lower extremity surgery was 7.6 and $8.41 \mathrm{mg}$ in two different trials. Another by Xu et al. (16) identified that the $\mathrm{ED}_{50}$ of ropivacaine for knee surgery was $9.71 \mathrm{mg}$. Dose-related studies with traditional LG SA have also been reported for other local anesthetic agents, such as bupivacaine. Lee et al. (15) showed that the $\mathrm{ED}_{50}$ of bupivacaine was $5.5 \mathrm{mg}$ when used in lower extremity surgery, while van Egmond et al. (17) reported that bupivacaine had an $\mathrm{ED}_{50}$ of $3.4 \mathrm{mg}$ and an $\mathrm{ED}_{95}$ of $5.4 \mathrm{mg}$ when used in knee surgery. Geng et al. (18) reported that the $\mathrm{ED}_{50}$ of bupivacaine for cesarean delivery was $7.53 \mathrm{mg}$, and Carvalho et al. (19) determined that bupivacaine had an $\mathrm{ED}_{50}$ of $9.8 \mathrm{mg}$ and an $\mathrm{ED}_{95}$ of $15 \mathrm{mg}$ when used in cesarean delivery.

Our previous study found that in real-time UG SA, the MLAD of $0.75 \%$ and $0.5 \%$ ropivacaine was 17.176 and $20.192 \mathrm{mg}$, respectively. In addition, we noted that for punctures at L4-5, the doses were significantly different from those used in traditional LG SA. Coincidentally, in a study of real-time UG SA, Liu et al. (20) found that administering $0.5 \%$ bupivacaine at $\mathrm{L} 5-\mathrm{S} 1$ had an $\mathrm{ED}_{90}$ of $25 \mathrm{mg}$, which was much higher than that of traditional LG SA. These studies suggest that the $\mathrm{ED}_{50}$ and $\mathrm{ED}_{90}$ values of local anesthetic agents required for real-time UG SA are significantly higher than those required for traditional LG SA.

Previous studies have shown that the accuracy of interlaminar space localization with US is higher than that via palpation (21). Locks Gde et al. (22) used US to verify the accuracy of palpation and found that the traditional reliance on anatomic landmarks for the localization of the L4 vertebral body or the L3-4 intervertebral space actually led to the localization of the L1-2, L2-3, L3-4, and L4-5 spaces in $4-7 \%, 33-47 \%, 49-53 \%$, and $7 \%$ of cases, respectively. Kim et al. (23) also found that the method of vertebral level determination by palpation was inaccurate and that the L4-5 space determined by palpation led to the localization of the L2-3, L3-4, L4-5, and L5-S1 in 5\%, $27 \%, 59 \%$, and $9 \%$ of cases, respectively. It is also well known that superiorly positioned SA will cause elevation of the plane block. Sharrock et al. (24) administered SA at different intervertebral spaces with $15 \mathrm{~mL}$ of $0.75 \%$ isobaric bupivacaine and found that the mean levels were T11 when administered at L5-S1, T7 when administered at L4-5, T5 
when administered at L3-4, and T3 when administered at L2-3. Taivainen et al. (25) infused different doses of $0.5 \%$ isobaric bupivacaine in the L4-5 intervertebral space and found that $3 \mathrm{~mL}$ of $0.5 \%$ isobaric bupivacaine was able to achieve blockade at a mean level of T12 and that $4 \mathrm{~mL}$ and $5 \mathrm{~mL}$ of $0.5 \%$ isobaric bupivacaine were able to achieve blockade at a mean level of T10. In other words, when puncture site approaches were more cephalad, a lower amount of local anesthetic was required to reach the same plane. However, such research poses further questions, such as whether there is a difference between the accuracy of palpation and US when determining the intervertebral space? And whether these differences further correlate to a difference in local anesthetic dosage.

To confirm if there is a real dosage difference between UG and LG SA (and the reason for any difference), the present study conducted a randomized controlled trial (RCT) of knee surgery patients to compare how the MLAD of ropivacaine at different concentrations differed between the two SA methods. We then determined the L4-5 intervertebral spaces by palpation and US, which was then followed by a C-arm X-ray examination to determine the actual spaces localized. Lastly, the two methods' accuracy and cephalic end positioning rate were compared to determine whether the positioning difference influenced the dosage difference. We present the following article in accordance with the CONSORT reporting checklist (available at https://dx.doi.org/10.21037/atm-21-3888).

\section{Methods}

\section{Study design}

Our clinical double-blind, randomized controlled trial (RCT) was designed as per the recommendations of the CONSORT Statement. The Ethics Committee of Fujian Provincial Hospital, Fuzhou, China approved the study protocol of on March 13, 2020 (approval No.: K2020$03-137)$, and the study protocol was registered on the Chinese Clinical Trial Registry website (registration No.: ChiCTR2000033158). The study was conducted as per the tenets of the Declaration of Helsinki (as revised in 2013), and the content of the study was thoroughly explained to the participants before written informed consent was obtained.

\section{Study population}

A total of 120 patients aged 18-65 years old were selected for our study. Each patient had a physical status of IIII following the American Society of Anesthesiologists (ASA) classification system and were scheduled to undergo selective knee surgery at the Fujian Provincial Hospital. Patients were excluded if they were found to have allergies to local anesthetic agents or non-steroidal antiinflammatory drugs, any contraindications to neuraxial anesthesia, obesity [body mass index (BMI) $>35 \mathrm{~kg} / \mathrm{m}^{2}$ ], or a history of spinal deformity or spinal surgery. The patients were randomly divided into four groups, categorized as follows: Group I: high ropivacaine ultrasound-guided (HRUG); Group II: low ropivacaine ultrasound-guided (LRUG), Group III: high ropivacaine landmark-guided (HRLG), and Group IV: low ropivacaine landmark-guided (LRLG). The high ropivacaine groups (HRGs: I/III) and the low ropivacaine groups (LRGs: II/IV) received a $0.75 \%$ and $0.5 \%$ concentration of ropivacaine, respectively. Patients were randomly allocated into groups with a ratio of 1:1:1:1 (30 patients per group) using a computer-generated simple randomization method. This included placing the random allocation sequence numbers and group names into opaque-sealed envelopes. The envelopes were then opened according to the order the patients were recruited, and each patient was grouped according to their allocation. Study statisticians generated the random allocation sequence, and subjects were enrolled by research assistants. The patients and the orthopedist which performed the radiographic localization were blind to grouping.

\section{Medications and procedures}

After being admitted to the operating room, each patient was continuously given oxygen $(3 \mathrm{~L} / \mathrm{min})$ inhalation through the nasal catheter, and their vital signs were monitored. Baseline blood pressure (BP) and heart rate (HR) were defined by the lowest $\mathrm{BP}$ and lowest HR recorded within $15 \mathrm{~min}$. After establishing venous access, all patients were intravenously administered $10 \mathrm{~mL} / \mathrm{kg}$ of sodium, potassium, magnesium, calcium, and glucose for $15 \mathrm{~min}$. No medications were given before SA. All patients were then placed in the lateral decubitus position for the operation.

Real-time UG SA was administered in the ultrasoundguided groups (I/II) using a Sonosite Edge portable color US system (Sonosite Inc., WA, USA). For the first confirmation, the sacrum and then the L-S1 space were located using sliding and tilting scanning techniques in paramedian sagittal oblique orientation with a $5-10 \mathrm{MHz}$ curved array transducer. The L4-5 intervertebral space 

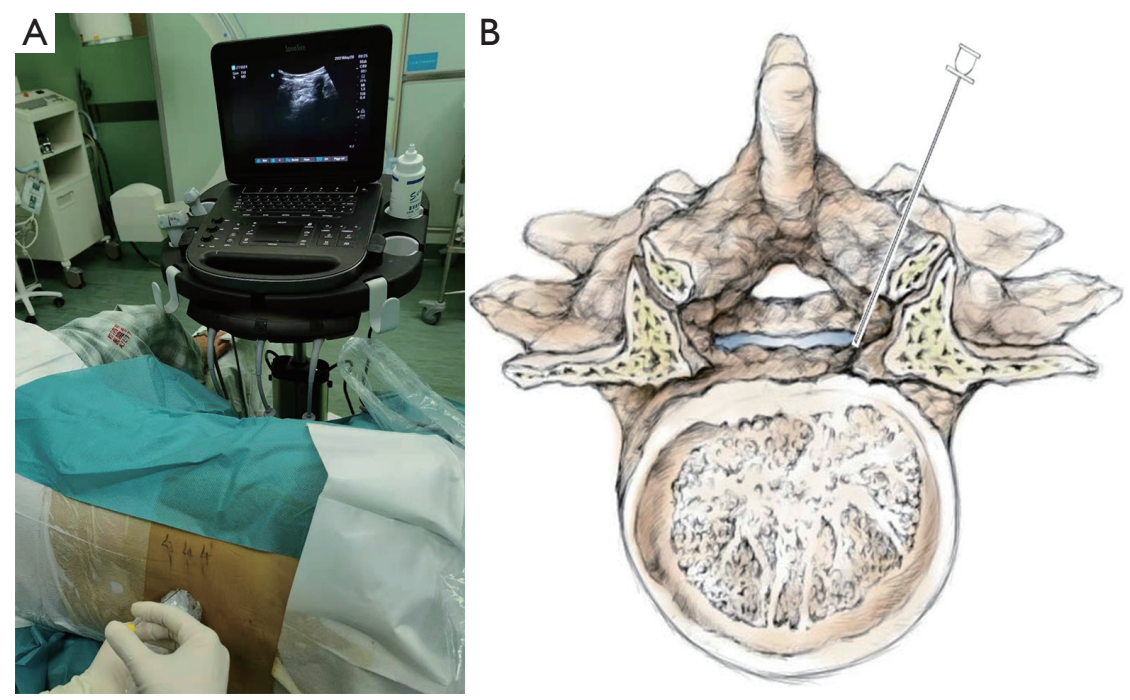

Figure 1 Real-time ultrasound-guided spinal anesthesia. (A) The short-axis in-plane US technique of anesthesia; (B) the schematic diagram of spinal canal transection and needle entry line.

was then identified by moving the transducer cephalad, and this point was marked on the skin. During the second confirmation, the T12 vertebra was confirmed at its joint with the 12 th rib. The transducer was then moved caudad to identify each consecutive intervertebral space descending to L4-5. The L4-5 space was reconfirmed, and another mark was made on the skin. The transducer was rotated $90^{\circ}$, parallel to the desired intervertebral space, and the distance from the skin to the anterior complex was measured by electronic calipers of the US machine to confirm the required depth for the insertion of the needle. After the surgical field was sterilized and towels were laid down for surgery, the probe was wrapped in a sterile protective sheath, and a local anesthetic infiltrated the puncture site. Taking a similar approach to our previous studies, the short-axis in-plane US technique (Figure $1 A, 1 B$ ), which was introduced by Liu et al. (7), was used to guide a 26 -gauge spinal needle puncture to the subarachnoid space, and the effectiveness was assessed by cerebrospinal fluid (CSF) outflow. After confirming a free-moving CSF outflow, the preordained dose of local anesthetic was diluted with the CSF to achieve the desired concentration of $0.75 \%$ or $0.5 \%$. The tip of the needle was then pointed in the cephalic direction, and a local anesthetic was injected at a rate of $0.4 \mathrm{~mL} / \mathrm{s}$. After the injection, the needle was removed, and the puncture point was covered with an aseptic dressing before returning the patient to the supine position.

In the traditional LG groups (III/IV), patients were positioned laterally, with their head and knees flexed, hands holding knees, and the shoulder line/intercristal line drawn parallel to each other and perpendicular to the floor. The L4-5 interspace was determined using Tuffier's line (an intercristal line drawn between the tops of both iliac crests) and marked on the skin. The local anesthesia site was punctured with a 26-gauge $S A$ needle, and the CSF outflow was used to assess if the puncture needle had effectively reached the subarachnoid space. After confirming the free flow of CSF, the same procedure was administered to the UG groups (I/II).

Another physician judged and recorded the actual intervertebral space at the marked site using a C-arm X-ray after marking. The anesthesiologist administering the SA would only be informed if the intervertebral space was higher than the L2-3 space. Patients among whom the localization was higher than L2-3 underwent repositioning to the L4-5 space using the C-arm X-ray and traditional LG SA. These patients were excluded from the experimental group. The actual level of the L4-5 space determined by palpation and US was recorded (verified by C-arm X-ray), and the rate of malposition was also recorded.

Dixon's up-and-down sequential method (26) was used to determine the subarachnoid level of medication. Based on previous clinical experience (8) and a previous study, the initial doses administered to the groups were $16 \mathrm{mg}$ (I), $18 \mathrm{mg}$ (II), $12 \mathrm{mg}$ (III), and $14 \mathrm{mg}$ (IV) [standard deviation (SD): 3.1]. A 1.5-mg dosage interval was used to 
meet the criteria that the dosage should be 0.5-2 times the anticipated SD. The blockade was considered successful if the sensory block reached the T10 plane within 20 min of the subarachnoid space injection and lasted for more than $60 \mathrm{~min}$. If this was not the case, the dosage was considered 'ineffective' and the dose was increased for the next patient. In contrast to this, if a dose was found to be 'effective', the next patient received a lower dose.

If a patient's BP decreased by either $>25 \%$ (compared to the preanesthetic status) or $<90 \mathrm{mmHg}$, intravenous ephedrine was administered. If the HR was under $55 \mathrm{bpm}$ in the perioperative period, $0.5 \mathrm{mg}$ of atropine was administered intravenously. For patients who experienced inadequate analgesia within $30 \mathrm{~min}$ of the injection, general anesthesia was administered.

\section{Assessment and evaluation}

A trained research assistant collected the baseline measurements, which included assessing sensory/motor blocks and their related data from the four groups during the perioperative period. The same anesthesiologist administered both types of SA and performed all assessments during SA and surgery.

The systolic blood pressure (SBP), diastolic blood pressure (DBP), respiratory rate (RR), HR, and oxygen saturation $\left(\mathrm{SpO}_{2}\right)$ were each recorded at the following time points: before anesthesia (T1), 5 min after injection (T2), $10 \mathrm{~min}$ after injection (T3), $15 \mathrm{~min}$ after injection (T4), and 20 min after injection (T5).

The sensory nerve block was assessed using a cold stimulation test (CST). After the subarachnoid injection, the plane of the sensory block was measured every 2 min for the first $20 \mathrm{~min}$. For patients among whom the blockade was considered 'effective', the sensory block was evaluated every $15 \mathrm{~min}$ after $30 \mathrm{~min}$ of the subarachnoid injection unless the sensory block had completely resolved. The time required for the sensory block to reach the T10 plane and the length of time for which the sensory block plane remained above the $\mathrm{T} 10$ plane were recorded.

The modified Bromage scale ( $0-3$ points) was used to assess the motor block based on the following grading system: 0 points, no motor loss; 1 point, inability to flex the hip; 2 points, inability to flex the knee; and 3 points, inability to flex the ankle. The onset time of the motor block (the time taken to reach 1 point on the Bromage scale), and the duration of the motor block (the time taken for the Bromage score to return to 0 points), were recorded.
Incidence of hypotension, nausea and vomiting, bradycardia, respiratory depression, and ephedrine and atropine use were recorded during surgery. On the first postoperative day, the resting visual analog scale (VAS) score, motoring VAS score, nausea and vomiting, headache, urinary retention, epidural hematoma, and nerve injury were recorded.

\section{Statistical analyses}

In this study, we used Dixon's up-and-down sequential method. The standard error of the initially administered drug doses could be predicted to be $\sigma \sqrt{ }(2 / \mathrm{N})$. With an $\alpha$ error of 0.05 and power of 0.8 , the sample size was estimated to be 20 using the formula 2(SD/SEM) ${ }^{2}(14)$. Having anticipated a $20 \%$ dropout rate, a minimum of 25 patients were required for each group. As described in the flowchart, we successfully enrolled 30 patients in each group. The dosage interval was set at $1.5 \mathrm{mg}$ in our study design to meet the requirement that the dosage should be 0.5-2 times the anticipated SD.

Data with normal distributions were described as the mean and SD, and between-group comparisons were performed using a one-way analysis of variance (ANOVA). Skewed data were presented as the median (interquartile range) and compared using the Kruskal-Wallis test. MLAD values with $95 \%$ confidence intervals (CIs) were calculated using the ordinal method and validated via probability unit regression analysis before being compared using oneway ANOVA. The accuracy of L4-5 localization for both approaches, the probability of cephalad localization, and the probability of caudal localization were determined using a McNemar's test. All statistical analyses were performed using SPSS version 20.0 software (IBM, NY, USA). Analysis items with $\mathrm{P}<0.05$ were considered statistically significant.

\section{Results}

A total of 128 patients who were admitted to undergo elective knee surgery between June 2020 and January 2021 were enrolled in this study. Among them, eight patients were excluded for the following reasons: 1 was allergic to local anesthetics, 3 were obese, and 5 refused to participate. This left 120 patients to be included in the study, each of which was randomly assigned to one of four groups (I, II, III, IV: 30 patients per group). A flowchart of patient enrolment and allocation is shown in Figure 2. There were no significant differences in the baseline characteristics 


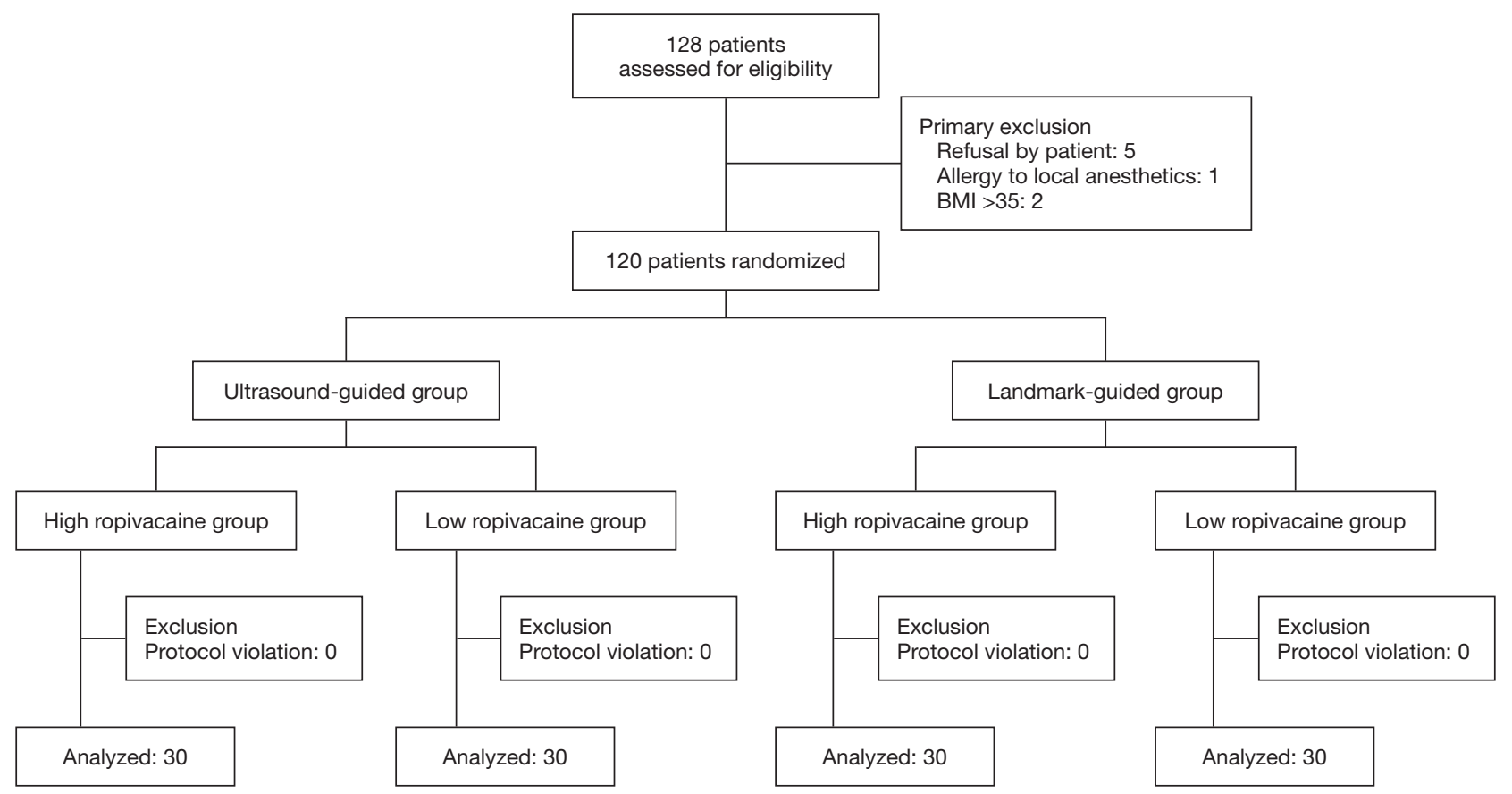

Figure 2 Consolidated standards of reporting trials, summarized in a flow diagram representing participant recruitment.

Table 1 Baseline patient characteristics of the four groups

\begin{tabular}{|c|c|c|c|c|c|}
\hline Characteristics & Group I & Group II & Group III & Group IV & $\mathrm{P}$ \\
\hline Sex, M/F, n & $15 / 15$ & $17 / 13$ & $13 / 17$ & $15 / 15$ & 0.692 \\
\hline Height, cm & $165.53 \pm 7.22$ & $168.83 \pm 7.99$ & $166.23 \pm 7.44$ & $167.27 \pm 6.85$ & 0.500 \\
\hline Weight, kg & $60.20 \pm 8.13$ & $61.63 \pm 8.83$ & $59.80 \pm 7.23$ & $61.13 \pm 9.47$ & 0.735 \\
\hline ASA physical status (I/II/III), $n$ & $4 / 20 / 6$ & $3 / 24 / 3$ & $3 / 22 / 5$ & $5 / 19 / 6$ & 0.793 \\
\hline
\end{tabular}

Data represents the number of patients or the mean \pm SD. Group I: HRUG; Group II: LRUG; Group III: HRLG; Group IV: LRLG. M, male; F, female; ASA, American Society of Anesthesiologists.

(age, sex, height, weight, duration of surgery, ASA status) between the four groups $(\mathrm{P}>0.05)$ (Table 1). The analysis of the four groups by Dixon's up-and-down sequential method is presented in Figure 3.

\section{MLAD of ropivacaine in the four groups}

In Group I (HRUG: $0.75 \%$ ) the MLAD was determined to be $17.176 \mathrm{mg}$ (95\% CI, 16.276-18.124) using Dixon's up-and-down sequential method and $17.417 \mathrm{mg}$ (95\% CI, 15.850-19.833) using the probit regression model (Table 2).
In Group II (LRUG: $0.05 \%$ ) the MLAD was determined to be $20.192 \mathrm{mg}$ (95\% CI, 19.256-21.174 mg) using Dixon's up-and-down sequential method and $20.396 \mathrm{mg}$ (95\% CI, 19.231-21.903 mg) using the probit regression model. These results suggest the MLAD of Group II $(0.05 \%$ ropivacaine) was significantly higher than that of Group I ( $0.75 \%$ ropivacaine $)(\mathrm{P}<0.001)$.

In Group III (HRLG: $0.75 \%$ ) the MLAD was determined to be $13.201 \mathrm{mg}$ (95\% CI, 11.959-14.571) using Dixon's up-and-down sequential method and $13.597 \mathrm{mg}$ (95\% CI, 12.334-14.934) using the probit regression model. 

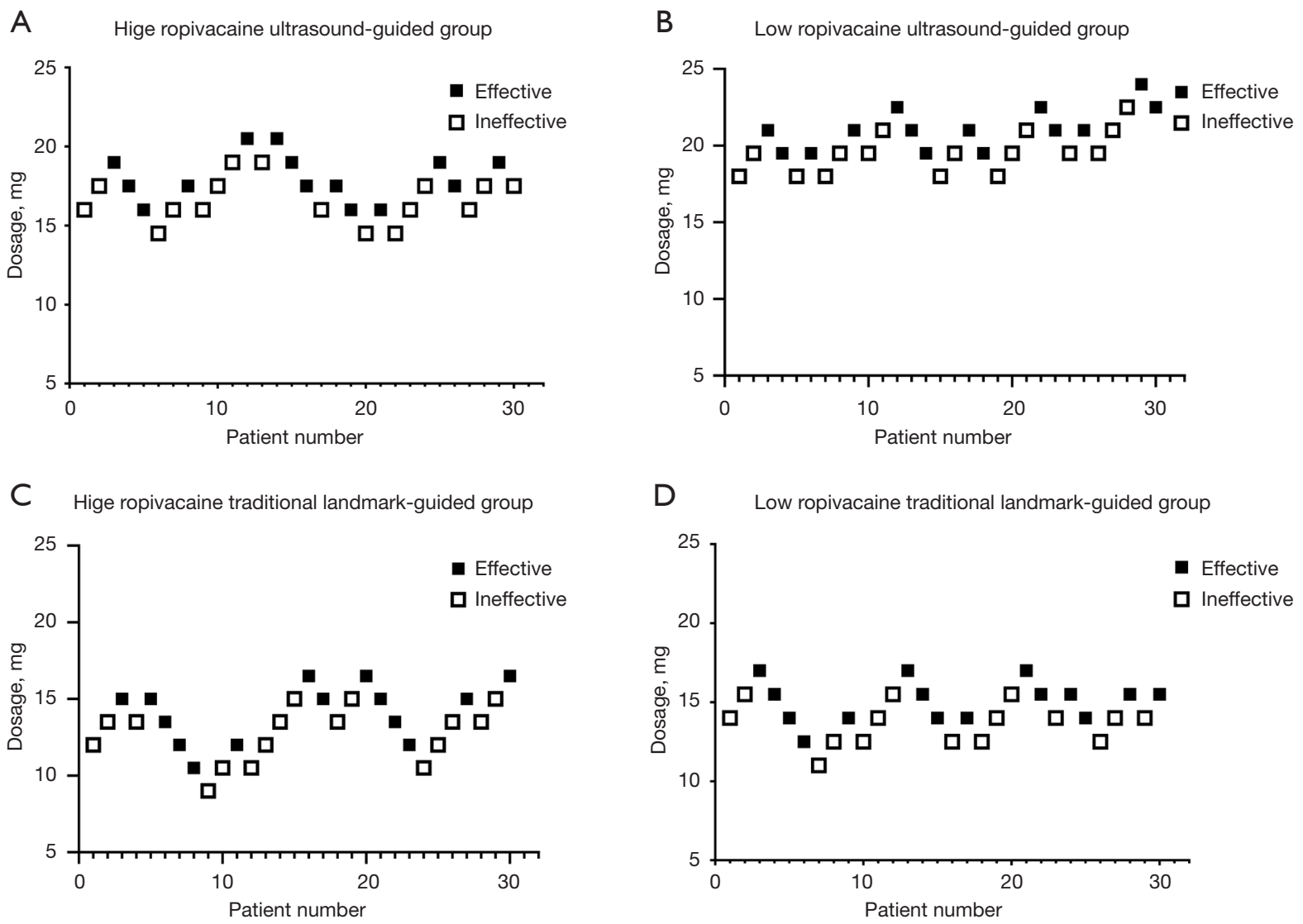

Figure 3 A sequence of effective and ineffective blocks. All findings used Dixon's up-and-down sequential method. (A) The HRUG group; (B) the LRUG group; (C) the HRLG group; (D) the LRLG group. ' $\square$ ': effective anesthesia. ' $\square$ ': ineffective anesthesia.

Table 2 Analysis of the four groups by Dixon's up-and-down sequential method

\begin{tabular}{|c|c|c|c|c|}
\hline Index & Group I & Group II & Group III & Group IV \\
\hline \multicolumn{5}{|c|}{ Dixon's sequential method } \\
\hline MLAD & 17.176 & 20.192 & 13.201 & 14.478 \\
\hline $95 \% \mathrm{Cl}$ & $16.276-18.124$ & $19.256-21.174$ & $11.959-14.571$ & $13.524-15.500$ \\
\hline \multicolumn{5}{|c|}{ Probity regression } \\
\hline $95 \% \mathrm{Cl}$ & $15.850-19.833$ & $19.231-21.903$ & $12.334-14.934$ & $13.364-15.743$ \\
\hline
\end{tabular}

ANOVA was used to compare the MLAD of the four groups $(P<0.01)$, and the comparison between each group $(P<0.05)$.

In Group IV (LRLG: 0.5\%) the MLAD was determined to be $14.478 \mathrm{mg}$ (95\% CI, 13.524-15.500) using Dixon's up-and-down sequential method and $14.556 \mathrm{mg}(95 \% \mathrm{CI}$, 13.364-15.743) using the probit regression model. These results suggest the MLAD of Group IV ( $0.05 \%$ ropivacaine) was significantly higher than that of Group III $(0.75 \%$ ropivacaine) $(\mathrm{P}=0.047)$.

In the HRGs, the UG subgroup (I) had a significantly higher MLAD than the LG subgroup (III) $(\mathrm{P}<0.001)$. Similarly, in the LRGs, the UG subgroup (II) had a significantly higher MLAD than the LG subgroup (IV) $(\mathrm{P}<0.001)$. 
Table 3 Details of the sensory and motor block procedures

\begin{tabular}{|c|c|c|c|c|c|}
\hline Variable & Group I & Group II & Group III & Group IV & $\mathrm{P}$ \\
\hline Reached time of T10 & $18.064 \pm 1.948$ & $16.714 \pm 1.790$ & $17.308 \pm 1.888$ & $17.333 \pm 2.127$ & 0.341 \\
\hline Duration of time above T10 & $97.357 \pm 12.965$ & $90.143 \pm 13.163$ & $88.357 \pm 12.953$ & $93.067 \pm 14.018$ & 0.318 \\
\hline The highest plane & $T_{11}\left(T_{9}-T_{12}\right)$ & $\mathrm{T}_{11}\left(\mathrm{~T}_{9}-\mathrm{T}_{12}\right)$ & $\mathrm{T}_{11}\left(\mathrm{~T}_{8}-\mathrm{T}_{12}\right)$ & $\mathrm{T}_{11}\left(\mathrm{~T}_{9}-\mathrm{T}_{12}\right)$ & 0.934 \\
\hline Onset time & $15.267 \pm 3.383$ & $16.400 \pm 2.894$ & $14.667 \pm 3.457$ & $15.867 \pm 3.739$ & 0.204 \\
\hline Duration time & $128.000 \pm 24.197$ & $112.833 \pm 19.693$ & $122.000 \pm 21.838$ & $109.000 \pm 15.492$ & 0.024 \\
\hline
\end{tabular}

The only statistically significant difference between the four groups was in the duration of the motor block. Data is presented as the mean \pm SD.

\section{Sensory block and motor block in the four groups}

No significant difference in the sensory block was observed between the four groups (Table 3). The time taken by the sensory block plane to reach the T10 for the four groups was $18.064 \pm 1.948 \mathrm{~min}(\mathrm{I}), 16.714 \pm 1.790 \mathrm{~min}$ (II), $17.308 \pm 1.888 \mathrm{~min}$ (III), and $17.333 \pm 2.127 \mathrm{~min}$ (IV). The duration for which the sensory block plane remained above the T10 level was $97.357 \pm 12.965 \mathrm{~min}(\mathrm{I}), 90.143 \pm 13.163 \mathrm{~min}$ (II), $88.357 \pm 12.953 \mathrm{~min}$ (III), and $93.067 \pm 14.018 \mathrm{~min}$ (IV). The highest plane sensory block reached in the four groups was T11 (T9-T12) (I), T11 (T9-T12) (II), T11 (T8-T12) (III), and T11 (T9-T12) (IV).

The time to the onset of motor block in the four groups was $15.267 \pm 3.383 \mathrm{~min}$ (I), $16.400 \pm 2.894 \mathrm{~min}$ (II), $14.667 \pm 3.457 \mathrm{~min}(\mathrm{III})$, and $15.867 \pm 3.739 \mathrm{~min}$ (IV). There were no differences in the time to the onset of the motor block among the groups. The durations of motor block for the four groups were $128.000 \pm 24.197$ (I), $112.833 \pm 19.693$ (II), $122.000 \pm 21.838$ (III), and $109.000 \pm 15.492 \mathrm{~min}$ (IV). There were differences in the time to the onset of motor block between the HRGs and LRGs for the same SA method ( $\mathrm{P}=0.0257$ for Group I vs. Group II; $\mathrm{P}=0.0290$ for Group III vs. Group IV). For the same concentration of ropivacaine, there was no significant difference in the duration of the motor block when using UG SA and traditional LG SA ( $\mathrm{P}=0.8366$ for Group I vs. Group III; $\mathrm{P}=0.978$ for Group II vs. Group IV).

The modified Bromage score for the four groups at different times is shown in Figure 4. The degree of the motor block in the HRGs was higher than that in the LRGs. However, there were no significant differences in the motor block between the HRGs and LRGs.
The proportion of the modified Bromage score of 3 points in the HRGs was significantly higher than that in the LRGs at $14-105 \mathrm{~min}$. This difference was statistically significant at $14,18,30,75$, and $90 \mathrm{~min}(\mathrm{P}<0.05)$. After $18 \mathrm{~min}$, the proportion of the modified Bromage score of 3 points in the HRGs was more than $50 \%$ for the first time, whereas the proportion of the modified Bromage score of 3 points in the LRGs was more than $50 \%$ for the first time at $45 \mathrm{~min}$. The proportion of the modified Bromage score of 3 points in the HRGs first decreased to less than $50 \%$ at $105 \mathrm{~min}$, while the proportion of the modified Bromage score of 3 points in the LRGs first decreased to less than $50 \%$ at $75 \mathrm{~min}$. The respective durations of the modified Bromage score of 3 points were 80.1 and $80.6 \mathrm{~min}$ in the HRGs compared with 36.5 and $33.6 \mathrm{~min}$ in the LRGs. We found that higher concentrations of ropivacaine could achieve greater degrees of motor block more quickly and maintain higher motor block levels for longer periods than lower concentrations of ropivacaine.

\section{Vertebral level determined by US and palpation}

The L4-5 space determined by US and palpation were examined by lumbar $\mathrm{X}$-ray (using a $\mathrm{C}$-arm $\mathrm{X}$-ray) and recorded the actual intervertebral space and cephalad or caudal localization. US correctly identified L4-5 in up to $90 \%$ of cases. Among mislocalizations, the incidence rate of mistaking L3-4 for L4-5 was 6.7\%, and the incidence rate of mistaking L5-S1 for L4-5 was 3.3\%. Comparatively, palpation was successful in only $33.3 \%$ of cases, with a $66.7 \%$ probability of cephalad localization errors, of which L3-4 was localized in $40 \%$ of cases, L2-3 in $23.3 \%$ of 
A
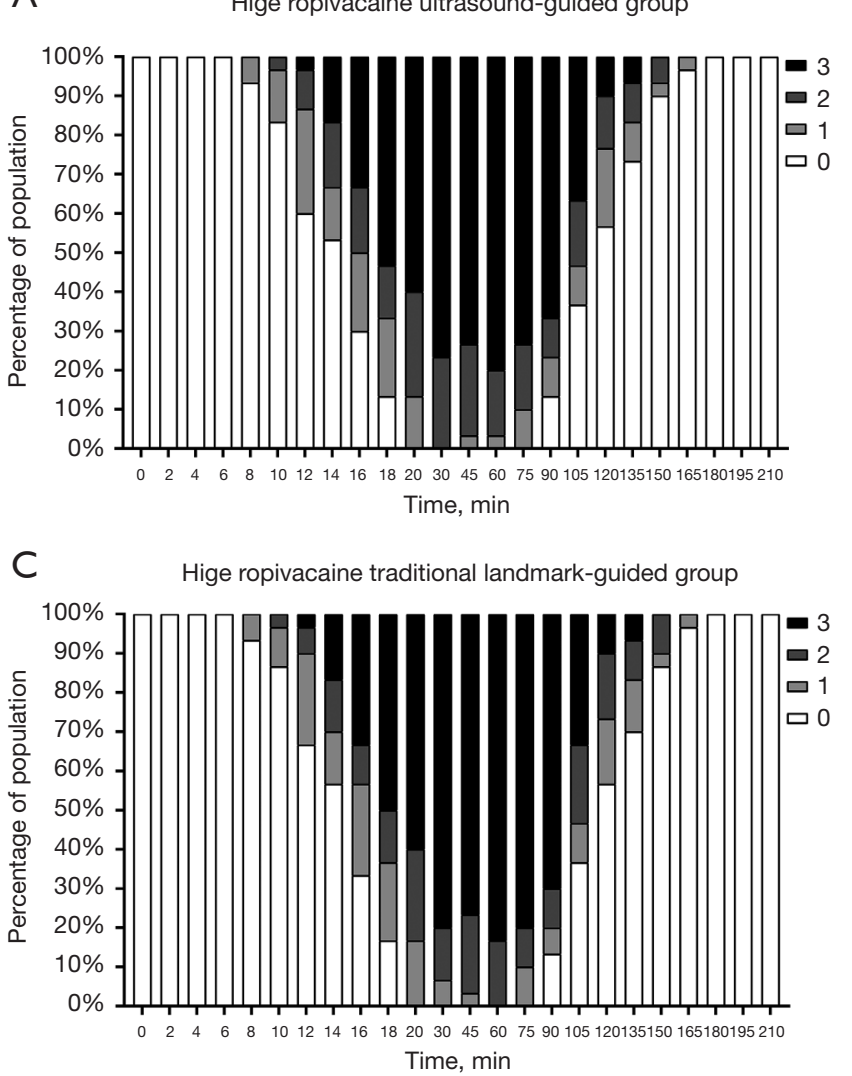

B Low ropivacaine ultrasound-guided group

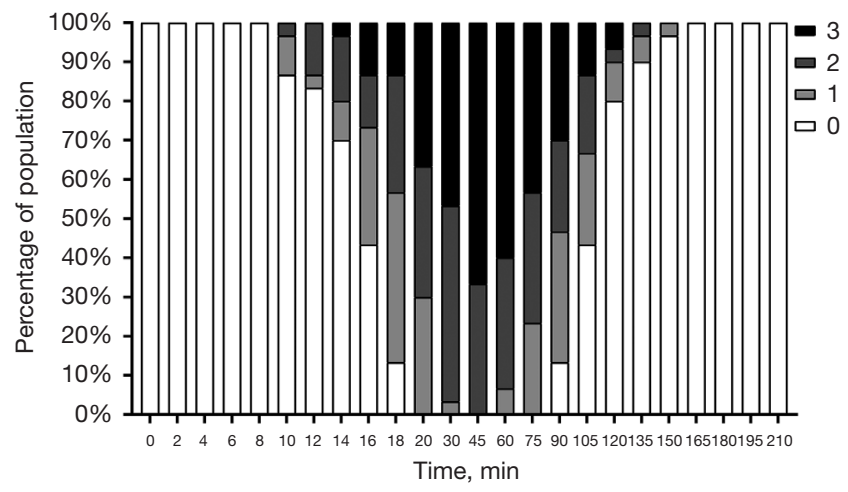

$\mathrm{D}$

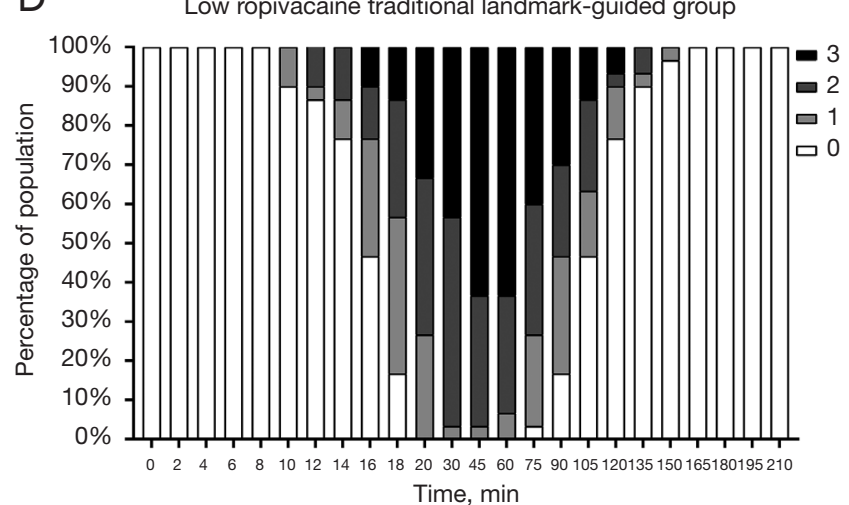

Figure 4 The modified Bromage scale for each group at different times. (A) The HRUG group; (B) the LRUG group; (C) the HRLG group; (D) the LRLG group. The degree of motor block in the HRGs was higher than that in the LRGs.

Table 4 The actual intervertebral space determined by US and palpation

\begin{tabular}{lccccc}
\hline \multirow{2}{*}{ Method } & \multicolumn{5}{c}{ The actual intervertebral space } \\
\cline { 2 - 5 } & L1-2 & L2-3 & L3-4 & L4-5 & L5-S1 \\
\hline Palpation & $2(3.3 \%)$ & $14(23.3 \%)$ & $24(40 \%)$ & $20(33.3 \%)$ & 0 \\
Ultrasound & 0 & 0 & $4(6.7 \%)$ & $54(90 \%)$ & $2(3.3 \%)$ \\
\hline
\end{tabular}

cases, and L1-2 in 3.3\% of cases (Tables 4,5, Figures 5-7). Ultimately, this meant the success rate of correctly identifying L4-5 by US was $90 \%$, whereas palpation was $33.3 \%(\mathrm{P}=0.011)$. The rate of cephalad localization by US was $6.67 \%$, while palpation was $66.67 \%(\mathrm{P}=0.002)$, and the rate of caudal localization by US was $3.3 \%$ and by palpation was $0 \%(\mathrm{P}<0.001)$.

\section{Changes in vital signs in the four groups}

Comparisons between the values of spontaneous bacterial peritonitis (SBP) and diastolic blood pressure (DBP) in the four groups at different times are shown in Figure 8. No significant differences were observed among the four groups in the data recorded for SBP at the following time points: before anesthesia (T1), $5 \mathrm{~min}$ after injection (T2), $10 \mathrm{~min}$ after injection (T3), $15 \mathrm{~min}$ after injection (T4), and $20 \mathrm{~min}$ after injection (T5) $(\mathrm{P}=0.9496)$. Moreover, there were no significant differences in DBP among the four groups $(\mathrm{P}=0.8802)$.

The RR, HR, and $\mathrm{SpO}_{2}$ levels of the patients in the four groups at different time points are shown in Figure 8. We 
Table 5 US and palpation localization errors identified through X-ray

\begin{tabular}{lcccc}
\hline \multirow{2}{*}{ Method } & \multicolumn{4}{c}{ Identified by X-ray } \\
\cline { 2 - 5 } & $\mathrm{n}$ & Errors identified with X-ray, $\mathrm{n}(\%)$ & Errors in a cranial direction, $\mathrm{n}(\%)$ & Errors in a caudal direction, $\mathrm{n}(\%)$ \\
\hline Palpation & 60 & $40(66.67)$ & $40(66.67)$ & 0 \\
Ultrasound & 60 & $6(10.0)$ & $4(6.67)$ & $2(3.33)$ \\
$\mathrm{P}$ & - & 0.011 & 0.002 & $<0.001$ \\
\hline
\end{tabular}

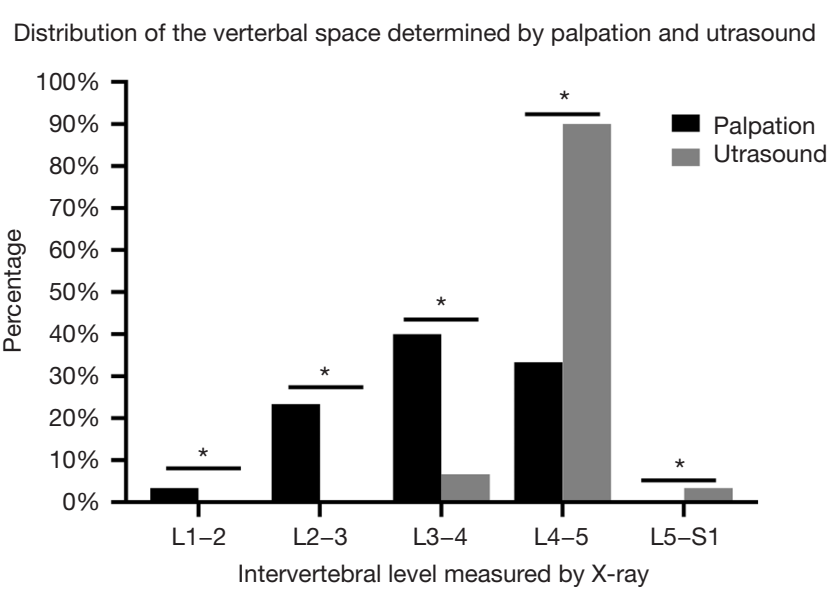

Figure 5 The actual intervertebral level when L4-5 space was determined by US and palpation. The success rates of correctly identifying L4-5 by US and palpation were $90 \%$ and $33.3 \%$, respectively. Determining the intervertebral space by palpation was problematic and had a high error rate which can easily lead to cephalad localization. * the intervertebral space determined by US compared to palpation $\mathrm{P}<0.05$.

found no significant differences in the RR, $\mathrm{HR}$, and $\mathrm{SpO}_{2}$ levels at the five aforementioned time points $(\mathrm{P}=0.6459$ for $\mathrm{RR}, \mathrm{P}=0.6885$ for $\mathrm{HR}$, and $\mathrm{P}=0.5778$ for $\mathrm{SpO}_{2}$ ).

\section{Incidences of adverse reactions in the four groups}

Comparisons of adverse reaction incidences during and after surgery among the four groups are shown in Table 6. During surgery, hypotension was observed among 2 patients $(6.7 \%)$ in Group I, 1 in Group III (3.3\%), and 1 in Group IV (3.3\%). Of the entire cohort, 1 (3.3\%) patient experienced bradycardia, while none of the patients experienced respiratory depression. 1 patient $(3.3 \%)$ in Group I experienced nausea and vomiting. There were no significant differences in the incidences of hypotension $(\mathrm{P}=0.562)$, nausea and vomiting $(\mathrm{P}=0.392)$, bradycardia $(\mathrm{P}=1)$, or respiratory depression $(\mathrm{P}=1)$ among the four groups. None of the patients in the cohort had postoperative headaches, nerve injuries, or epidural hematoma. However, 1 patient (3.3\%) in each of the HRGs experienced urinary retention, while no patient in the LRGs did; this difference was not statistically significant $(\mathrm{P}=0.569)$.

\section{Discussion}

Dixon's modified sequential method is a simple and efficient way of calculating the MLAD required for SA as it considers both drug concentration or dose with the isometric arrangement of the subjects. The concentrations or doses administered to the patients in this study were determined by the results of previous patients. In this way, the data of most patients suggested a positive reaction rate of around $50 \%$.

In a previous study, we demonstrated that for lower limb surgery the MLAD values of $0.75 \%$ and $0.5 \%$ ropivacaine were $17.176 \mathrm{mg}(0.75 \%)$ and $20.192 \mathrm{mg}(0.5 \%)$ when using real-time UG SA to achieve a sensory blockade at the T10 level, while for LG SA the MLAD of ropivacaine was mostly between 7.6-12.8 mg (13-16). Previous studies have also shown that the $\mathrm{ED}_{50}$ of ropivacaine for reaching the T6 level of sensory block during cesarean sections under $\mathrm{SA}$ was $6.8-11.4 \mathrm{mg}(27-30)$, and the $\mathrm{ED}_{50}$ of ropivacaine required to reach the T5 level was $5.92-8.35 \mathrm{mg}$ (31). Kallio et al. (32) studied inguinal hernia repair under SA and found that administering $15 \mathrm{mg}$ of ropivacaine allowed $97 \%$ of patients to achieve a sensory block plane within 5-20 min of reaching above the T10 level, and also allowed them to remain above T10for $90 \mathrm{~min}$. The highest plane of sensory block that could be reached was T5 (T2-9). In a study of transurethral resection of the prostate under SA, Chaudhary et al. (33) found that a level above T10 (T8-10) could be achieved in all patients with $15 \mathrm{mg}$ ropivacaine. As the MLAD of ropivacaine in real-time UG SA is much higher than the dose used in LG SA, we applied Dixon's modified 

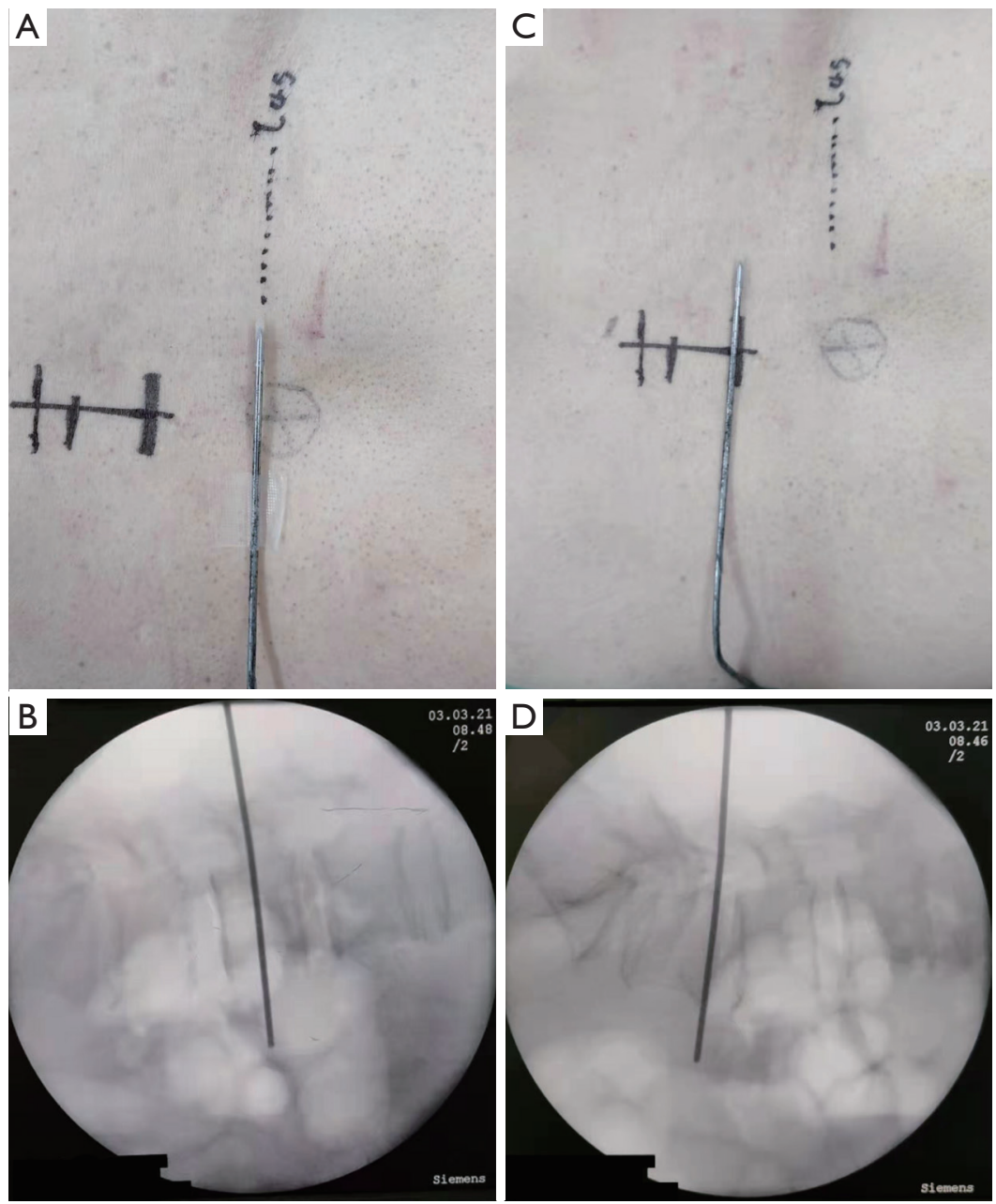

Figure 6 The L4-5 space determined by palpation with poor accuracy. (A) The metal marker put in the L4-5 space determined by palpation; (B) the corresponding X-ray image of Figure $6 \mathrm{~A}$ showed the mental marker that was located in the middle of the L4 intervertebral; (C) the metal marker put in the L4-5 space that was determined by lumber X-ray; (D) the corresponding X-ray image of Figure 6C.
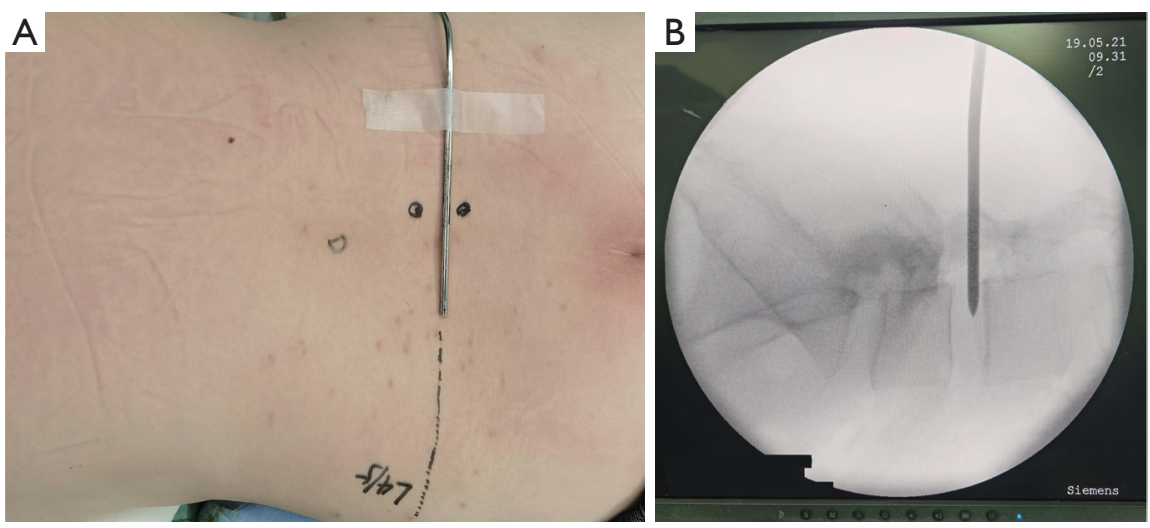

Figure 7 The ultrasonic localization of the L4-5 space was consistent with lumber X-ray. (A) The metal marker put in the L4-5 space determined by US; (B) the lumber X-ray showed the metal marker that was located in the L4-5 intervertebral space. 

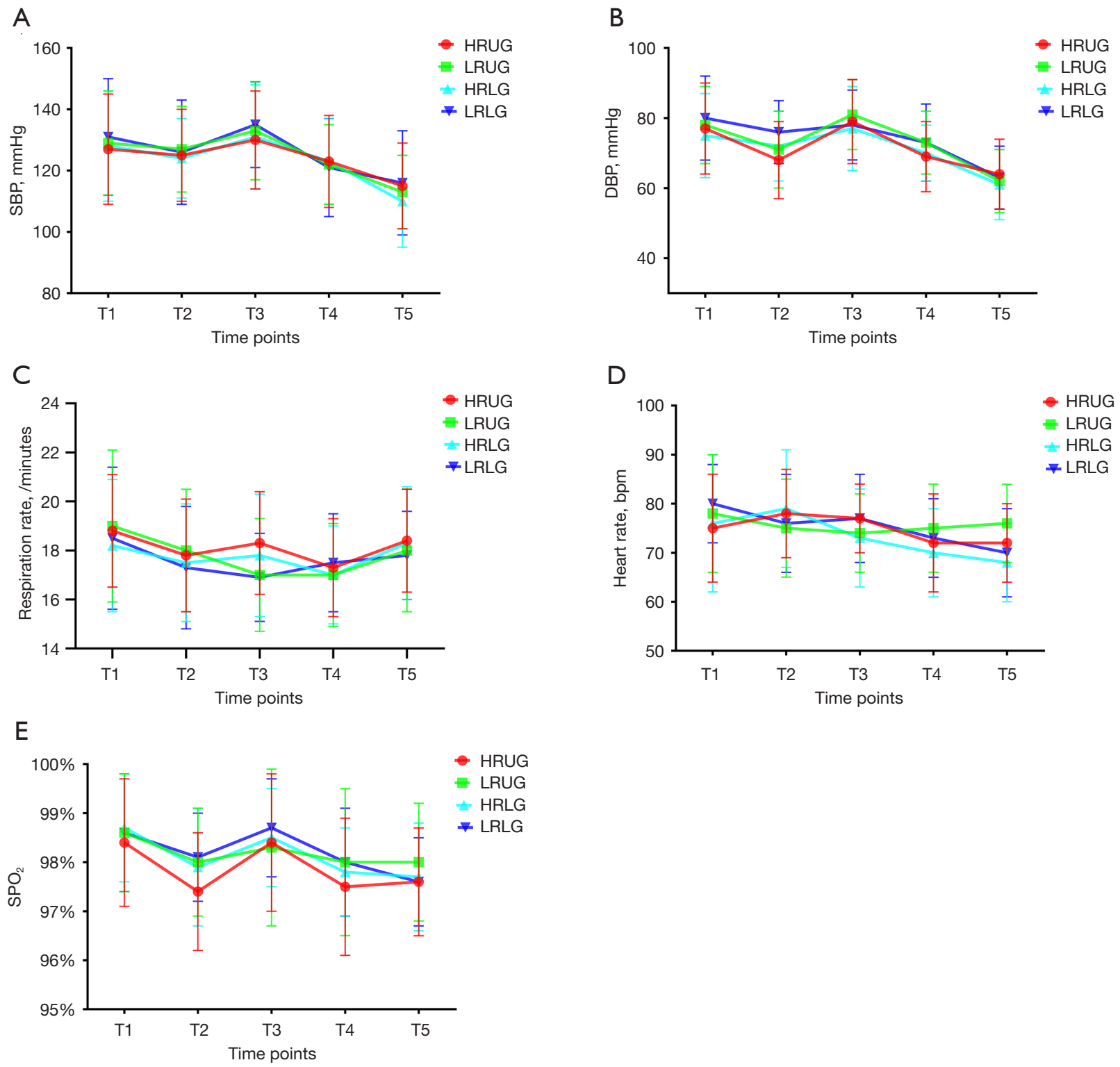

Figure 8 Comparison of vital signs between the 4 patient groups at different time points. (A) SBP; (B) DBP; (C) RR; (D) HR; (E) SpO . There were no statistically significant differences between the four groups at any of the time points $(\mathrm{P}>0.05)$. SBP, systolic blood pressure; DBP, diastolic blood pressure; $\mathrm{RR}$, respiratory rate; $\mathrm{HR}$, heart rate; $\mathrm{SpO}_{2}$, oxygen saturation.

sequential method to calculate the MLAD of ropivacaine at different concentrations for the two different SA methods. It is well known that the factors that influence the blockade level in SA mainly include the dose, volume, injection rate, and puncture point. Sheskey et al. (34) studied the effects of volume and dose on the blockade level and found that both factors affected the block plane, although the dose exerted a greater effect. As the drug dose is a product of the volume and concentration, the concentration was fixed for each group in this study and the dose for each patient was adjusted to the appropriate volume. For the 30 patients in the same concentration group, the volume of ropivacaine differed slightly due to their dose differences. However, the dose exerted a greater effect on the block plane and therefore we found that the volume difference caused by the dose difference could be excluded from the study. Horlocker et al. (35) investigated the effect of injection rates on the sensory level during SA and found higher levels of 
Table 6 Incidence of adverse reactions during and after surgery (n, \%)

\begin{tabular}{|c|c|c|c|c|c|}
\hline Adverse reactions & Group I & Group II & Group III & Group IV & $\mathrm{P}$ \\
\hline Bradycardia & $1(3.3)$ & $1(3.3)$ & $1(3.3)$ & $1(3.3)$ & - \\
\hline Respiratory depression & 0 & 0 & 0 & 0 & - \\
\hline Nausea and vomiting & $1(3.3)$ & 0 & 0 & 0 & 0.392 \\
\hline Nerve injury & 0 & 0 & 0 & 0 & - \\
\hline Uroschesis & $1(3.3)$ & 0 & $1(3.3)$ & 0 & 0.569 \\
\hline Epidural hematoma & 0 & 0 & 0 & 0 & - \\
\hline
\end{tabular}

No statistical significance was observed between the four groups.

block with faster injection rates. However, more scholars believe that the cephalad bias of the intervertebral space might influence the elevation of the block plane. In a study of SA at L2-3 and L4-5, Tuominen et al. (36) found that the median level of sensory block when SA was administered at L2-3 was T7, while the median level of sensory block when SA was administered at L4-5 was T11. Another study by Taivainen et al. (37) examined the influence of obesity on the spread of spinal analgesia after injection of plain $0.5 \%$ bupivacaine into the L3-4 or L4-5 interspace. They found that the use of the L3-4 interspace instead of L4-5 resulted in a higher mean spread of block in both patients with high (T4 vs. T8) and normal (T9 vs. T11) body mass index (BMI). In a further study of SA at L2-3 and L4-5, Chin et al. (38) found that the median levels of sensory block when SA was administered into the L2-3 and L4-5 interspaces were T6.4 and T10.3, respectively. To verify whether the two methods of SA influenced the MLAD due to positioning errors, we set the infusion rate at $0.4 \mathrm{~mL} / \mathrm{s}$ in the present study, avoiding the impact of different injection rates on our results. For the traditional LG SA groups (III, IV), the MLAD values of $0.75 \%$ and $0.5 \%$ ropivacaine were 13.201 and $14.478 \mathrm{mg}$, whereas for the UG SA groups (I, II), the respective MLAD values were 17.176 and $20.192 \mathrm{mg}$. The UG SA groups were noted to have a significantly higher MLAD than the traditional LG SA groups.

As the HRGs and LRGs received similar volumes of ropivacaine at the same rates of injection, we were left to wonder if the differences in MLAD were caused by differences in the localization of the intervertebral space. Previous studies have shown that the accuracy of intervertebral space determination by palpation to be only $30 \%$ (39), and that the localization errors were greater than or equal to two intervertebral spaces. With the development of US technology and the clarity of ultrasonic spinal anatomy, the accuracy of ultrasonic localization has already far surpassed that, reaching $70-90 \%$ (21). In addition, the margin of error never exceeded one level when using the US method. By using a plain X-ray of the lumbar spine as a reference standard, Furness et al. (39) demonstrated that US correctly identified individual interspaces $71 \%$ of the time, whereas palpation was noted to be successful only $29 \%$ of the time.

Furthermore, the intervertebral space was up to two spaces higher or lower in $27 \%$ of the cases determined by palpation, whereas the margin of error for US (as mentioned previously) was no more than one level. In a different study, Broadbent et al. (40) used magnetic resonance imaging (MRI) as a reference standard and verified that the accuracy of interspace determination by palpation was $29 \%$. These results determined that the interspace in their study was one space higher than assumed in $51 \%$ of cases, 2 spaces higher than assumed in $15.5 \%$ of cases, 3 spaces higher than assumed in 1\% of cases, 4 spaces higher than assumed in $0.5 \%$ of cases, and lower than assumed in only $3 \%$ of cases. Watson et al. (41) studied the accuracy of ultrasonic localization with MRI, and found that US accurately identified the L3-4 interspace in $76.5 \%$ of cases with a margin of error that did not exceed one level.

Several comparative studies have investigated intervertebral space localization by palpation and US. Lee et al. (42) found that the estimates of the spinal level of the intercristal line determined by palpation only agreed with US measurements $14 \%$ of the time, was 1 level higher than the US measurements $23 \%$ of the time, and 2 or more levels higher than the US measurements $25 \%$ 
of the time. Another study by Schlotterbeck et al. (43) found that the estimates of the spinal level determined by palpation agreed with the US measurements $36.4 \%$ of the time, while the intervertebral space was determined by palpation with $93.7 \%$ mislocalization from the L4-5 space. All instances of mislocalization were also identified as having a biased cephalad. Margarido et al. (44) also found that the L4-5 interspaces determined by palpation were all higher than the actual L4-5 level. In summary, determining the intervertebral space by palpation can be problematic as it has a high error rate and can easily lead to cephalad localization. For this reason, in the present study, we used a $\mathrm{C}$-arm X-ray of the lumbar to verify the actual localization levels when L4-5 localization was attempted with the two different SA methods.

Our previous study of real-time UG SA showed that the MLAD in response to low concentrations of ropivacaine was higher than that of high concentrations of ropivacaine and that the duration of motor block was shorter with low concentrations of ropivacaine. We reconfirmed these findings in the present study. By assessing the modified Bromage scores at different time points, we found that regardless of whether US or traditional landmarks determined localization, the degree of motor block was lower in the $0.5 \%$ ropivacaine group than that of the $0.75 \%$ ropivacaine group who displayed more obvious manifestations of sensory-motor dissociation. From this, we have determined that a $0.5 \%$ concentration of ropivacaine is more suitable as a SA agent among patients who require early postoperative ambulation to promote rapid recovery. However, it is necessary to note that insufficient muscle relaxation can occur due to early regression of the motor blockade during lower extremity surgery.

Here we should also note that our study had several limitations. Firstly, although $\mathrm{ED}_{50}$ is generally used to measure the potency of ropivacaine, it only represents the dose or concentration level at which $50 \%$ of the population exhibits a response. Therefore, to some extent, the $\mathrm{ED}_{50}$ has limited utility in clinical practice. Secondly, patients in both the UG and LG SA groups only received single injection agents, and the time of sensory block could not be prolonged with the prolongation of operation time. Thirdly, as we administered SA into the L4-5 space, the influence of injection location on the dose should be considered when interpreting the data from this SA study regarding other injection locations.

Regarding the mechanism underlying the differences in MLAD, we only limited our study to the differences in intervertebral space location and did not study the differences in needle angle. Compared with traditional LG SA, there is an approximately $45^{\circ}$ angle between the needle entry point and the sagittal plane of the back during UG SA. Different needle entry angles may also affect the spread of local anesthetics within the spinal canal, leading to dosage differences between the two SA methods. This phenomenon needs to be explored further in future studies.

\section{Conclusions}

Real-time UG SA requires a higher MLAD of ropivacaine at the L4-5 level than traditional LG SA. This may be due to LG SA resulting in less accurate localization, which leads to more cephalad localization. Regarding the different concentrations of ropivacaine (regardless of whether SA was UG or LG), we found that $0.5 \%$ ropivacaine results in a shorter motor blockade time and is more beneficial for early postoperative ambulation and accelerating postoperative rehabilitation.

\section{Acknowledgments}

Funding: This study was funded by the National Natural Science Foundation of China (82171186); High-level hospital foster grants from Fujian Provincial Hospital, Fujian Province, China (2019HSJJ23); High-level hospital foster grants from Fujian Provincial Hospital, Fujian Province, China (2019HSJJ21); Training Project for Talents of Fujian Provincial Health Commission (2019-ZQN-1); Provincial special subsidy funds for health care of Fujian Provincial Department of Finance (No. 2020467); Fujian Science and Technology Innovation Joint Foundation (Major Program) (2019Y9028); Natural Science Foundation of Fujian Province (2020J011078); Medical Innovation Project of Fujian Province (2020CXB002); Fujian Undergraduate Education and Teaching Reform Research Major Project (FBJG20200022); Education and Teaching Reform Research Project of Fujian Medical University (J20001).

\section{Footnote}

Reporting Checklist: The authors have completed the CONSORT reporting checklist. Available at https://dx.doi. org/10.21037/atm-21-3888 
Trial Protocol: Available at https://dx.doi.org/10.21037/atm21-3888

Data Sharing Statement: Available at https://dx.doi. org/10.21037/atm-21-3888

Conflicts of Interest: All authors have completed the ICMJE uniform disclosure form (available at https://dx.doi. org/10.21037/atm-21-3888). All authors reported that this study was funded by the Natural Science Foundation of Fujian Province (2018J01246); High-level hospital foster grants from Fujian Provincial Hospital, Fujian Province, China (2019HSJJ23); High-level hospital foster grants from Fujian Provincial Hospital, Fujian Province, China (2019HSJJ21); Training Project for Talents of Fujian Provincial Health Commission (2019-ZQN-1); Provincial special subsidy funds for health care of Fujian Provincial Department of Finance (No. 2020467); Fujian Science and Technology Innovation Joint Foundation (Major Program) (2019Y9028); Natural Science Foundation of Fujian Province (2020J011078); Medical Innovation Project of Fujian Province (2020CXB002); Fujian Undergraduate Education and Teaching Reform Research Major Project (FBJG20200022); Education and Teaching Reform Research Project of Fujian Medical University (J20001). The authors have no other conflicts of interest to declare.

Ethical Statement: The authors are accountable for all aspects of the work in ensuring that questions related to the accuracy or integrity of any part of the work are appropriately investigated and resolved. The Ethics Committee of Fujian Provincial Hospital, Fuzhou, China approved the study protocol of on March 13, 2020 (approval No.: K2020-03-137), and the study protocol was registered on the Chinese Clinical Trial Registry website (registration No.: ChiCTR2000033158). The study was conducted as per the tenets of the Declaration of Helsinki (as revised in 2013), and the content of the study was thoroughly explained to the participants before written informed consent was obtained.

Open Access Statement: This is an Open Access article distributed in accordance with the Creative Commons Attribution-NonCommercial-NoDerivs 4.0 International License (CC BY-NC-ND 4.0), which permits the noncommercial replication and distribution of the article with the strict proviso that no changes or edits are made and the original work is properly cited (including links to both the formal publication through the relevant DOI and the license). See: https://creativecommons.org/licenses/by-nc-nd/4.0/.

\section{References}

1. Olawin AM, J, M. D. in StatPearls (StatPearls Publishing Copyright (C) 2021, StatPearls Publishing LLC., 2021). Available online: https://www.ncbi.nlm.nih.gov/books/ NBK537299/

2. Conroy PH, Luyet C, McCartney CJ, et al. Real-time ultrasound-guided spinal anaesthesia: a prospective observational study of a new approach. Anesthesiol Res Pract 2013;2013:525818.

3. Brinkmann S, Tang R, Sawka A, et al. Single-operator realtime ultrasound-guided spinal injection using SonixGPS ${ }^{\mathrm{Tм}}$ : a case series. Can J Anaesth 2013;60:896-901.

4. Zheng T, Ye P, Wu W, et al. Minimum local anesthetic dose of ropivacaine in real-time ultrasound-guided intraspinal anesthesia for lower extremity surgery: a randomized controlled trial. Ann Transl Med 2020;8:861.

5. Wang Q, Yin C, Wang TL. Ultrasound facilitates identification of combined spinal-epidural puncture in obese parturients. Chin Med J (Engl) 2012;125:3840-3.

6. Karmakar MK, Li X, Ho AM, et al. Real-time ultrasoundguided paramedian epidural access: evaluation of a novel in-plane technique. Br J Anaesth 2009;102:845-54.

7. Liu Y, Qian W, Ke XJ, et al. Real-time Ultrasound-guided Spinal Anesthesia Using a New Paramedian Transverse Approach. Curr Med Sci 2018;38:910-3.

8. Lee PJ, Tang R, Sawka A, et al. Brief report: real-time ultrasound-guided spinal anesthesia using Taylor's approach. Anesth Analg 2011;112:1236-8.

9. Elsharkawy H, Maheshwari A, Babazade R, et al. Realtime ultrasound-guided spinal anesthesia in patients with predicted difficult anatomy. Minerva Anestesiol 2017;83:465-73.

10. Chin KJ, Chan VW, Ramlogan R, et al. Real-time ultrasound-guided spinal anesthesia in patients with a challenging spinal anatomy: two case reports. Acta Anaesthesiol Scand 2010;54:252-5.

11. Niazi AU, Chin KJ, Jin R, et al. Real-time ultrasoundguided spinal anesthesia using the SonixGPS ultrasound guidance system: a feasibility study. Acta Anaesthesiol Scand 2014;58:875-81.

12. Hansen TG. Ropivacaine: a pharmacological review. Expert Rev Neurother 2004;4:781-91.

13. Sell A, Olkkola KT, Jalonen J, et al. Minimum effective local anaesthetic dose of isobaric levobupivacaine and 
ropivacaine administered via a spinal catheter for hip replacement surgery. Br J Anaesth 2005;94:239-42.

14. Lee YY, Ngan Kee WD, Chang HK, et al. Spinal ropivacaine for lower limb surgery: a dose response study. Anesth Analg 2007;105:520-3.

15. Lee YY, Ngan Kee WD, Fong SY, et al. The median effective dose of bupivacaine, levobupivacaine, and ropivacaine after intrathecal injection in lower limb surgery. Anesth Analg 2009;109:1331-4.

16. Xu T, Wang J, Wang G, et al. Relative potency ratio between hyperbaric and isobaric solutions of ropivacaine in subarachnoid block for knee arthroscopy. Int J Clin Exp Med 2015;8:9603-6.

17. van Egmond JC, Verburg H, Derks EA, et al. Optimal dose of intrathecal isobaric bupivacaine in total knee arthroplasty. Can J Anaesth 2018;65:1004-11.

18. Geng ZY, Wang DX, Wu XM. Minimum effective local anesthetic dose of intrathecal hyperbaric ropivacaine and bupivacaine for cesarean section. Chin Med J (Engl) 2011;124:509-13.

19. Carvalho B, Collins J, Drover DR, et al. ED(50) and $\mathrm{ED}(95)$ of intrathecal bupivacaine in morbidly obese patients undergoing cesarean delivery. Anesthesiology 2011;114:529-35.

20. Liu Y, Yang S, Yao W, et al. Minimum effective dose of plain bupivacaine $0.5 \%$ for ultrasound-guided spinal anaesthesia using Taylor's approach. Br J Anaesth 2020;124:e230-1.

21. Perlas A, Chaparro LE, Chin KJ. Lumbar Neuraxial Ultrasound for Spinal and Epidural Anesthesia: A Systematic Review and Meta-Analysis. Reg Anesth Pain Med 2016;41:251-60.

22. Locks Gde F, Almeida MC, Pereira AA. Use of the ultrasound to determine the level of lumbar puncture in pregnant women. Rev Bras Anestesiol 2010;60:13-9.

23. Kim H, Won D, Chang JE, et al. Ultrasound assessment of the anatomic landmarks for spinal anesthesia in elderly patients with hip fracture: A prospective observational study. Medicine (Baltimore) 2019;98:e16388.

24. Sharrock NE, Lesser ML, Gabel RA. Segmental levels of anaesthesia following the extradural injection of $0.75 \%$ bupivacaine at different lumbar spaces in elderly patients. Br J Anaesth 1984;56:285-7.

25. Taivainen T, Tuominen M, Rosenberg PH. Spread of spinal anaesthesia using various doses of plain $0.5 \%$ bupivacaine injected at the LIV-V interspace. Acta Anaesthesiol Scand 1989;33:652-5.

26. Dixon WJ. Staircase bioassay: the up-and-down method.
Neurosci Biobehav Rev 1991;15:47-50.

27. Mei Z, Ngan Kee WD, Sheng ZM, et al. Comparative dose-response study of hyperbaric ropivacaine for spinal anesthesia for cesarean delivery in singleton versus twin pregnancies. J Clin Anesth 2020;67:110068.

28. Tang Y, Yang M, Fu F, et al. Comparison of the ED50 of intrathecal hyperbaric ropivacaine co-administered with or without intrathecal dexmedetomidine for cesarean section: A prospective, double-blinded, randomized dose-response trial using up-down sequential allocation method. J Clin Anesth 2020;62:109725.

29. Wang HZ, Chen HW, Fan YT, et al. Relationship Between Body Mass Index and Spread of Spinal Anesthsia in Pregnant Women: A Randomized Controlled Trial. Med Sci Monit 2018;24:6144-50.

30. Zhang $\mathrm{W}, \mathrm{Wu} \mathrm{H}$. ED50 of intrathecal ropivacaine for cesarean section under prophylactic infusion of phenylephrine: A consort study. Medicine (Baltimore) 2017;96:e8319.

31. Yu X, Zhang F. The effect of parturient height on the median effective dose of intrathecally administered ropivacaine. Ann Saudi Med 2016;36:328-33.

32. Kallio H, Snäll EV, Suvanto SJ, et al. Spinal hyperbaric ropivacaine-fentanyl for day-surgery. Reg Anesth Pain Med 2005;30:48-54.

33. Chaudhary A, Bogra J, Singh PK, et al. Efficacy of spinal ropivacaine versus ropivacaine with fentanyl in transurethral resection operations. Saudi J Anaesth 2014;8:88-91.

34. Sheskey MC, Rocco AG, Bizzarri-Schmid M, et al. A doseresponse study of bupivacaine for spinal anesthesia. Anesth Analg 1983;62:931-5.

35. Horlocker TT, Wedel DJ, Wilson PR. Effect of injection rate on sensory level and duration of hypobaric bupivacaine spinal anesthesia for total hip arthroplasty. Anesth Analg 1994;79:773-7.

36. Tuominen M, Taivainen T, Rosenberg PH. Spread of spinal anaesthesia with plain $0.5 \%$ bupivacaine: influence of the vertebral interspace used for injection. Br J Anaesth 1989;62:358-61.

37. Taivainen T, Tuominen M, Rosenberg PH. Influence of obesity on the spread of spinal analgesia after injection of plain $0.5 \%$ bupivacaine at the L3-4 or L4-5 interspace. Br J Anaesth 1990;64:542-6.

38. Chin KW, Chin NM, Chin MK. Spread of spinal anaesthesia with $0.5 \%$ bupivacaine: influence of the vertebral interspace and speed of injection. Med J Malaysia 1994;49:142-8. 
39. Furness G, Reilly MP, Kuchi S. An evaluation of ultrasound imaging for identification of lumbar intervertebral level. Anaesthesia 2002;57:277-80.

40. Broadbent CR, Maxwell WB, Ferrie R, et al. Ability of anaesthetists to identify a marked lumbar interspace. Anaesthesia 2000;55:1122-6.

41. Watson MJ, Evans S, Thorp JM. Could ultrasonography be used by an anaesthetist to identify a specified lumbar interspace before spinal anaesthesia? Br J Anaesth 2003;90:509-11.

42. Lee AJ, Ranasinghe JS, Chehade JM, et al. Ultrasound assessment of the vertebral level of the intercristal line in

Cite this article as: Zheng T, Zheng CY, Yan LP, Guo HL, You Y, Ye P, Hu B, Zheng XC. Comparing the minimum local anesthetic dose of ropivacaine in real-time ultrasoundguided spinal anesthesia and traditional landmark-guided spinal anesthesia: a randomized controlled trial of knee surgery patients. Ann Transl Med 2021;9(19):1492. doi: 10.21037/atm21-3888 pregnancy. Anesth Analg 2011;113:559-64.

43. Schlotterbeck H, Schaeffer R, Dow WA, et al.

Ultrasonographic control of the puncture level for lumbar neuraxial block in obstetric anaesthesia. Br J Anaesth 2008;100:230-4.

44. Margarido CB, Mikhael R, Arzola C, et al. The intercristal line determined by palpation is not a reliable anatomical landmark for neuraxial anesthesia. Can J Anaesth 2011;58:262-6.

(English Language Editors: J. Goetz and J. Chapnick) 